\title{
Ovit Dağbaşı Gölü Suyunda Doğal Radyoaktivite Konsantrasyonlarının Belirlenmesi
}

\author{
Serdar DİMAN ${ }^{1}$, Selim SARI ${ }^{2}$ \\ ${ }^{1}$ Recep Tayyip Erdoğan Üniversitesi, Fen Edebiyat Fakültesi, Fizik Bölümü, Rize, Türkiye \\ ${ }^{2}$ Recep Tayyip Erdoğan Üniversitesi, Lisansüstü Eğitim Enstitüsü, Fizik Anabilim Dalı, Rize, Türkiye \\ ${ }^{*}$ Sorumlu Yazar/Corresponding Author \\ E-mail: serdar.dizman@erdogan.edu.tr \\ Araștırma makalesi/Research article \\ Geliş tarihi/Received:19.04.2021 \\ Orcid ID: 0000-0002-6511-9526 \\ Kabul tarihi/Accepted: 11.05.2021
}

\section{ÖZET}

Doğada yaşayan tüm canlılar sürekli olarak doğal ve yapay radyasyon kaynaklarından yayınlanan iyonlaştırıcı radyasyona maruz kalmaktadır. $\mathrm{Bu}$ nedenle, yaşam alanları ve ziyaret edilen bölgelerde radyoaktivite düzeylerinin belirlenmesi önemlidir. Bu çalışmada, Rize ili İkizdere ilçesine bağlı İkizdere-İspir karayolu üzerinde bulunan Ovit Dağbaşı Gölünden alınan su örneklerinde ${ }^{226} \mathrm{Ra},{ }^{232} \mathrm{Th}$ ve ${ }^{40} \mathrm{~K}$ radyoaktivite konsantrasyonları yüksek saflıkta germanyum dedektörü (HPGe) kullanılarak, ${ }^{3} \mathrm{H}$ radyoaktivite konsantrasyonları ise sıvı sintilasyon sayacı (LSC) kullanılarak belirlendi. Su örneklerinde ${ }^{226} \mathrm{Ra},{ }^{232} \mathrm{Th},{ }^{40} \mathrm{~K}$ ve ${ }^{3} \mathrm{H}$ radyoizotop konsantrasyonlarının sirasiyla $0,36-2,82 \mathrm{~Bq} / \mathrm{L}, 0,37-1,92 \mathrm{~Bq} / \mathrm{L}, 13,28-20,96 \mathrm{~Bq} / \mathrm{L}$ ve 2,51-3,53 $\mathrm{Bq} / \mathrm{L}$ aralı̆̆ında değiştiği belirlendi. Ortalama radyoaktivite konsantrasyonları ise ${ }^{226} \mathrm{Ra}$ için $1,80 \pm 0,54 \mathrm{~Bq} / \mathrm{L}$, ${ }^{232} \mathrm{Th}$ için $1,13 \pm 0,51 \mathrm{~Bq} / \mathrm{L},{ }^{40} \mathrm{~K}$ için $17,22 \pm 2,61 \mathrm{~Bq} / \mathrm{L}$ ve ${ }^{3} \mathrm{H}$ için $2,88 \pm 0,47 \mathrm{~Bq} / \mathrm{L}$ olarak bulunmuştur. Bulunan aktivite konsantrasyonları uluslararası kuruluşlar tarafından önerilen değerlerle kıyaslandığında, önerilen değerler aralığında oldukları belirlendi. Sonuç olarak, yapılan çalışma ile Ovit Dağbaşı Gölü ziyaretçileri için incelenen radyoiztoplardan kaynaklı radyoaktivitenin bir sağlık riski oluşturmayacağı gösterilmiştir.

Anahtar Kelimeler: Doğal radyoaktivite, Trityum, Göl suyu, Rize

\section{Determination of Natural Radioactivity Concentrations in Ovit Dağbaşı Lake Water}

\begin{abstract}
All living creatures in nature are constantly exposed to ionizing radiation emitted from natural and artificial radiation sources. For this reason, it is important to monitor the levels of radioactivity in living spaces and visited areas. In this study, ${ }^{226} \mathrm{Ra},{ }^{232} \mathrm{Th},{ }^{40} \mathrm{~K}$ and ${ }^{3} \mathrm{H}$ concentrations in water samples taken from Ovit Dağbaşı Lake located on İkizdere-İspir highway in İkizdere district of Rize province were determined using a high purity germanium detector and a liquid scintillation counter. It was determined that ${ }^{226} \mathrm{Ra},{ }^{232} \mathrm{Th},{ }^{40} \mathrm{~K}$ and ${ }^{3} \mathrm{H}$ radioisotope concentrations in the water samples varied between 0.36-2.82 Bq/L, 0.37-1.92 Bq/L, 13.28-20.96 $\mathrm{Bq} / \mathrm{L}$ ve $2.51-3.53 \mathrm{~Bq} / \mathrm{L}$, respectively. Mean radioactivity concentrations were found as $1.80 \pm 0.54 \mathrm{~Bq} / \mathrm{L}$ for ${ }^{226} \mathrm{Ra}, 1.13 \pm 0.51 \mathrm{~Bq} / \mathrm{L}$ for ${ }^{232} \mathrm{Th}, 17.22 \pm 2.61 \mathrm{~Bq} / \mathrm{L}$ for ${ }^{40} \mathrm{~K}$ and $2.88 \pm 0.47 \mathrm{~Bq} / \mathrm{L}$ for ${ }^{3} \mathrm{H}$. The activity concentrations found were compared with the values recommended by international organizations and were found to be as same as the recommended values. As a result, it has been shown with this study that the radioactivity caused by the examined radioisotopes will not pose a health risk for the visitors of Ovit Dağbaş1 Lake.
\end{abstract}

Keywords: Natural radioactivity, Trityum, Lake water, Rize 


\section{Giriş}

Doğada yaşayan bütün canlılar radyasyona maruz kalmaktadır. Tabiatta yerini alan çok uzun ömürlü radyoaktif elementler yaşadığımız çevrede normal ve kaçınılmaz olarak kabul edilen doğal bir radyasyon düzeyi oluşturmuşlardır. Doğal radyasyonlar, uzaydan gelen kozmik 1şınlar ile kaya, toprak, su ve havada bulunan doğal radyoaktif çekirdeklerin radyoaktif bozunuma uğramaları sonucu yayınlanan 1şınlardan ibarettir. Çevreye bu doğal kaynaklardan yayılmaktadırlar. İnsan, içinde yaşadığı doğal çevrede bulunan bu kaynaklardan yayınlanan değişik tipteki radyasyonlara belirli ölçülerde sürekli maruz kalmaktadır (UNSCEAR, 1993; Dizman vd., 2018).

Radyasyon dozu değerlendirilmelerinde doğal kaynaklar oldukça önemli yer tutarlar. Çünkü insanlar hayatları süresince doğal kaynaklardan yayınlanan radyasyonlardan belli oranlarda doz almaktadırlar (Dizman ve Mukhtarli, 2021).

Çevresel radyasyon ölçümlerindeki temel amaç, insanların çevresel kaynaklardan aldıkları radyasyon türünün yanında dozunun belirlenmesi ve oluşturacağı riskin değerlendirilmesidir. Bunun için de, doğal radyasyon kaynaklarını oluşturan radyonüklitlerin çevresel ortamdaki konsantrasyonları ile radyasyonun özellikle insanda olmak üzere, biyolojik sistemler üzerindeki tesirinin tayin edilmesi gerekir (Kavun vd., 2018). Ayrica, çevresel ortamda bulunan radyonüklitler ile insanların bu kaynaklardan aldıkları radyasyon dozu arasındaki ilişkinin de belirlenmesi gerekir. Ancak böyle bir araştırmadan sonra bir bölgenin doğal radyasyon açısından sağlıklı bir şekilde yaşamaya uygun olup olmadığına karar verilebilir (Otansev vd., 2016; Dizman vd., 2019).

Bu çalışmanın amacı, Rize ili İkizdere ilçesine bağlı İkizdere-İspir karayolu üzerinde bulunan Ovit Dağbaşı Gölünden alınan su örneklerinde doğal $\left({ }^{226} \mathrm{Ra},{ }^{232} \mathrm{Th},{ }^{40} \mathrm{~K}\right.$ ve $\left.{ }^{3} \mathrm{H}\right)$ radyoaktivite konsantrasyonlarını belirlemek ve bulunan sonuçların uluslararası kuruluşlar tarafından önerilen değerlerle kıyaslamasını yapmaktır. Dolayısıyla, Ovit Dağbaşı Gölünü ziyaret eden insanlar için radyolojik açıdan herhangi bir risk olup olmadığını belirlemektir.

\section{Materyal ve Metot}

\section{1. Çalışma Bölgesi}

Çalışma bölgesi, Rize ili İkizdere ilçesine bağlı İkizdere-İspir karayolu üzerinde bulunan ve rakımı 2733 metre olan Ovit Dağbaşı Gölü’dür (Şekil 1). Ovit Dağbaşı Gölü, yükselti etkilerinden buzullaşmaya maruz kalınması nedeniyle meydana gelen bir sirk (buzyalağı) gölüdür. Ovit Dağbaşı Gölü, Ovit Yayla yerleşmesine en yakın olan ve kolayca ulaşılabilen bir göl olduğu için bölgenin en bilinen ve en çok ziyaretçi alan gölüdür (URL1). Göl çevresinde kampların yapıldığı da bilinmektedir.

\section{2. Örneklerin Toplanması ve Analize Hazırlanması}

2019 y1lı Ekim ayında Ovit Dağbaşı Gölü’nün 1zgaralama yöntemiyle belirlenmiş küçük eşit alanlarının her birinden bir su numunesi olmak üzere toplamda 15 su numunesi toplandı (Şekil 1). Su numuneleri 1 litrelik plastik şişelerle alındı ve etiketlendi. Ayrıca, örnekleme yapılan her noktanın koordinatı GPS cihazı (Magellan Explorist 510) ile kaydedildi. Daha sonra laboratuvara getirilen numuneler, içlerinde bulunması muhtemel fiziksel partikülleri elimine etmek için filtre edildi.

${ }^{226} \mathrm{Ra}, \quad{ }^{232} \mathrm{Th}, \quad{ }^{40} \mathrm{~K} \quad$ konsantrasyonlarının belirlenmesi için filtre edilen örnekler darası alınmış sayım kaplarına konuldu ve ağırlıkları tartılarak etiketlendi. Hazırlanan örnek kapları, ağızları hava geçirmeyecek şekilde parafilmle sıkıca kapatılarak içerisinde bulunan radyoaktif bozunma ürünlerinin dengeye gelmesini sağlamak amaciyla yaklaşı bir ay süre ile bekletildi. Böylece, numuneler gama ölçümleri için hazır hale getirilmiş oldu. 
${ }^{3} \mathrm{H}$ (trityum) konsantrasyonlarının belirlenmesi için numuneler ilk olarak, damıtmasaflaştırma-ayrıştırma olarak bilinen destilasyon işlemine tabii tutuldu. $\mathrm{Bu}$ işlem, numunenin fiziksel ve kimyasal kirliliklerden arındırılması ve numuneler arasında farklılığa neden olabilecek etkenleri ortadan kaldırmak için yapılır. Daha sonra numuneler, ASTM metodunda belirtilen işlem basamaklarına göre hazırlandı (ASTM, D4107-08, 2006; Palomo vd., 2007). Hazırlanan örnekten $10 \mathrm{ml}$ alınarak
LSC ölçümlerinde kullanılan 20 ml'lik viale aktarıldı, üstüne de $10 \mathrm{ml}$ sintilatör (Ultima Gold LLT) eklendi. Homojen bir karışım olması için vial yaklaşık 30 saniye çalkalandı. Hazırlanan vialler, kimyasal reaksiyonlar nedeniyle oluşan kemilüminesans parıldamalarını elimine etmek için 2 gün karanlık bir ortamda bekletildi ve böylelikle Sıvı Sintilasyon Sayacında (LSC) ölçüme hazır hale getirilmiş oldu.

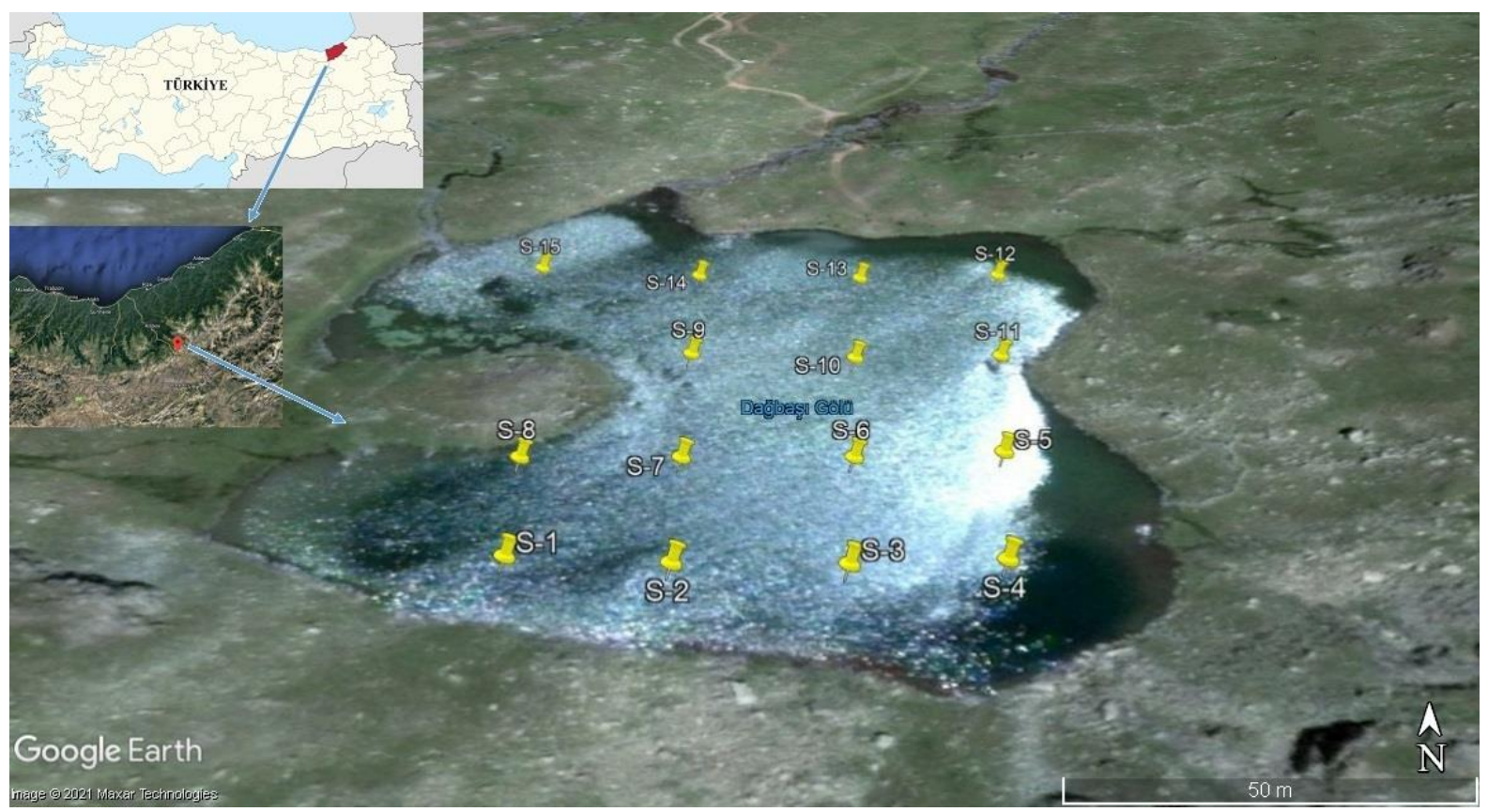

Şekil 1. Çalışma bölgesi ve örneklem noktaları

Figure 1. Study area and sampling points

\subsection{Radyoaktivitenin Belirlenmesi}

${ }^{226} \mathrm{Ra},{ }^{232} \mathrm{Th}$ ve ${ }^{40} \mathrm{~K}$ radyoaktivite ölçümleri $1332,5 \mathrm{keV}$ 'de $1,9 \mathrm{keV}$ ayırma gücüne ve \% 55'lik relatif verime sahip olan ORTEC marka (Model: GEM55P4-95) Yüksek Saflıkta Germanyum Dedektörü (HPGe) kullanılarak gerçekleştirildi. Gama spektrometre sistemi dedektör, önyükselteç, spektroskopi yükselteci, analog sayımları elektronik sinyallere dönüştüren ADC sistemi ve çok kanallı analizörden (MCA) ibarettir. Dedektörün numune odası inşaat malzemelerinden ve kozmik 1şınlardan gelen arkaplan (background) radyasyona karşı $10 \mathrm{~cm}$ kurşun blokla zırhlanmıştır. Hazırlanan örnekler dedektörde
50000 saniye sayıld1. Sayım sonucu elde edilen spektrumlar data analiz programı olan Gamma Vision ile değerlendirildi. $\quad{ }^{226} \mathrm{Ra}$ radyoizotopunun aktivite konsantrasyonunun belirlenmesi için ${ }^{214} \mathrm{~Pb}$ 'ün $295,2 \mathrm{keV}$ ve 352 $\mathrm{keV}$ ve ${ }^{214} \mathrm{Bi}$ 'ün $609,4 \mathrm{keV}$ enerjilerindeki piklerin alanı, ${ }^{232} \mathrm{Th}$ radyoizotopunun aktivite konsantrasyonunun belirlenmesi için ise ${ }^{208} \mathrm{Tl}$ 'in $583,1 \mathrm{keV}$ ve ${ }^{228} \mathrm{Ac}$ 'in $911,1 \mathrm{keV}$ enerjilerindeki piklerin alanları kullanıldı. ${ }^{40} \mathrm{~K}$ radyoizotopunun aktivite konsantrasyonunun hesaplanmasında ise $1460,8 \mathrm{keV}$ enerjisindeki pikin alanı kullanıld1. $\mathrm{Bu}$ radyoizotop enerjilerindeki piklerin alan değerleri ile su örneklerinde radyoaktivite konsantrasyonları denklem 1 kullanılarak hesaplandı. 


$$
A(B q / k g)=\frac{N}{\varepsilon . I_{\gamma} \cdot t . m}
$$

Burada $\mathrm{N}$ ilgilenilen enerjideki net alan, $\varepsilon$ ilgilenilen gama enerjisindeki verim, $\mathrm{I}_{\gamma}$ ilgilenilen enerjideki gama 1şınının bolluğu, $\mathrm{t}$ sayım süresi (s) ve m numune kütlesidir ( $\mathrm{kg}$ ).

Dedektörün algılamış olduğu gama sayımlarının asıl değerini belirlemek spektrumda gözlenen her bir pik için dedektör verimliliği tespit edilmelidir (Grigorescu vd., 2002). Bunun için, ${ }^{152} \mathrm{Eu}$ standart kaynağ 1 dedektör önüne konarak $10 \mathrm{dk}$ sayım gerçekleştirildi ve oluşan spektrumların sayım hızı değerleri elde edildi. $\mathrm{Bu}$ sayım hızı değerleri kullanılarak, ilgilenilen enerjilerdeki dedektör verimleri denklem 2 kullanılarak hesapland.

$$
\varepsilon=\frac{N}{A \cdot I_{\gamma \cdot t}}
$$

Burada, $\varepsilon$ ilgilenilen gama enerjisindeki verim, $\mathrm{N}$ ilgilenilen enerjideki net alan sayım, A verim kalibrasyonu için kullanılan standart kaynağın o anki aktivitesi (Bq), t sayım süresi (s) ve $I_{\gamma}$ ilgilenilen enerjideki gama ışınının bolluğudur.

Germanyum dedektöründe ilgili radyoizotoplar için minimum dedekte edilebilir aktivite değerleri denklem 3 kullanılarak hesaplandı (Curie, 1968).

$$
M D L(B q / k g)=\frac{4,66 \sqrt{B}}{\varepsilon . I_{\gamma} \cdot t . m}
$$

Burada B arkaplan (background) sayımının ilgilenilen enerjideki alanı, $\varepsilon$ ilgilenilen gama enerjisindeki verim, $I_{\gamma}$ ilgilenilen enerjideki gama ışınının bolluğu, $t$ sayım süresi (s) ve $\mathrm{m}$ numune kütlesidir (kg).

Numunelerdeki trityum konsantrasyonları, s1v1 sintilasyon sayac1 (Perkin Elmer, LSC Tricarb 2910 TR) ile belirlendi. LSC cihazının dedeksiyon verimi ile geri kazanım düzeltme faktörünü hesaplamak için 214S221 nolu tamamlanmış projeden alınmış olan sertifikalı
S1v1 trityum standard1 (Eckert \& Ziegler, P.O. No.: P700723, Source No.: 1676-44) kullanılarak laboratuvar (DWS) ve spike (RWS) standartları hazırlandı. Hazırlanan standartlar ve numuneler siv1 sintilasyon sayacinda 1500 dakika (150 dk x 10 tur) süre ile ölçüldü. LSC cihazının dedeksiyon verimi ve geri kazanım düzeltme faktörü sırasıyla denklem 4 ve 5 kullanılarak hesaplandı.

$$
\begin{aligned}
& \mathrm{E}=\frac{\mathrm{a}_{\mathrm{st}}-\mathrm{b}}{\mathrm{dpm}_{\mathrm{st}}} \\
& F=\frac{\mathrm{R}_{\mathrm{st}}-\mathrm{b}}{\mathrm{E} \cdot \mathrm{R}_{\text {sto }}}
\end{aligned}
$$

Burada E dedeksiyon verimi, a $a_{\text {st }}$ DWS standardının sayım konsantrasyonunun ortalaması (cpm), b background örneğinin sayım konsantrasyonunun ortalamas1 (cpm), $\mathrm{dpm}_{\mathrm{st}}$ DWS standardının ölçüm tarihindeki

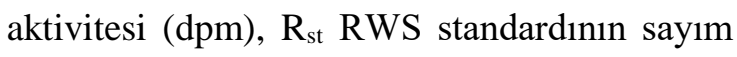
konsantrasyonunun ortalamas1 (cpm) ve $R_{\text {sto }}$ RWS standardının ölçüm tarihindeki aktivitesi (dpm)'dir. Numunelerdeki trityum aktivite konsantrasyonları $\mathrm{Bq} / \mathrm{L}$ biriminde denklem 6 kullanılarak hesaplandi.

$$
\mathrm{A}=\frac{(\mathrm{s}-\mathrm{b}) \cdot 1000}{60 . \mathrm{E} \cdot \mathrm{F} \cdot \mathrm{V}}
$$

Burada s numunelerin sayım konsantrasyonunun ortalamas1 (cpm), b background örneğinin sayım konsantrasyonunun ortalamas1 (cpm), E dedeksiyon verimi, $\mathrm{F}$ geri kazanım düzeltme faktörü ve V örnek miktarı (mL)'dır. Kullanılan LSC cihazı için minimum ölçülebilir aktivite (MDA) değeri denklem 7 kullanılarak hesaplandı (Currie, 1968).

$$
\operatorname{MDA}(\mathrm{Bq} / \mathrm{L})=\frac{3,29 \sqrt{\frac{R_{\mathrm{b}}}{t_{\mathrm{s}}}+\frac{R_{\mathrm{b}}}{t_{\mathrm{b}}}}+\frac{2,71}{t_{\mathrm{s}}}}{60 \text {.E.F.V }}
$$

Burada $\quad R_{b}$ background örneğinin sayım konsantrasyonu (cpm), $t_{s}$ örneklerin sayım süresi (dk), $t_{b}$ background örneğinin sayım süresi (dk), E dedeksiyon verimi, F geri kazanım düzeltme faktörü ve $\mathrm{V}$ örnek miktarı (L)'dır. 


\section{Bulgular ve Tartışma}

Trityum konsantrasyonlarının belirlenmesi için örnekler ve standartların LSC cihazında ölçümü sonrası alınan analiz sonuçlarına ilk olarak Chauvenet kriteri uyguland. Daha sonra Chauvenet kriteri uygulanmış DWS, RWS ve background standartlarının ortalama cpm (count per minute) değerleri DWS için 2377,67 cpm, RWS için 28,40 cpm ve BKG için 2,44 cpm olarak bulundu. Bu değerler kullanılarak verim değeri $\% 26$, geri kazanım düzeltme faktörü 1,09 ve MDA değeri ise $1,48 \mathrm{~Bq} / \mathrm{L}$ olarak hesaplandi. Hesaplanan verim ve geri kazanım düzeltme faktörü kullanılarak her bir örnek için trityum aktivite konsantrasyonları hesaplandi. Sulardaki trityum konsantrasyonu $\mathrm{Bq} / \mathrm{L}$ ya da trityum birimi (TU) olarak verilir. Trityum konsantrasyonunun Bq-TU ilişkisi 1 $\mathrm{TU}=1$ Trityum atomu $/ 1 \times 10^{18}$ hidrojen atomu=3,19 $\mathrm{pCi} / \mathrm{L}=0,118 \quad \mathrm{~Bq} / \mathrm{L} \quad$ olarak verilmektedir. Yani, $1 \times 10^{18}$ hidrojen atomuna karşı bir trityum atomunun bulunması "1 trityum birimi (TU)" olarak tanımlanır. Göl suyu örnekleri için elde edilen sonuçlar da hem $\mathrm{Bq} / \mathrm{L}$ hem de TU biriminde verilmiştir.
Ovit Dağbaşı Gölünden alınan su örneklerinde belirlenen trityum $\left({ }^{3} \mathrm{H}\right)$ aktivite konsantrasyonlar1 Tablo 1'de verilmektedir. Ayrıca, su örneklerinde belirlenen trityum konsantrasyonları Şekil 2'de grafiksel olarak gösterilmektedir. Göl suyu örneklerinde trityum konsantrasyonlar1 2,51 Bq/L $(21,24$ $\mathrm{TU})$ ile $3,53 \mathrm{~Bq} / \mathrm{L}(29,87 \mathrm{TU})$ aralığında değişmekte olup ortalama aktivite konsantrasyonu $2,88 \pm 0,47 \mathrm{~Bq} / \mathrm{L}(24,41 \pm$ 3,98 TU) olarak bulunmuştur. Hem ulusal hem de uluslararası kuruluşlar tarafından içme sularında trityum konsantrasyon değerlerinin belli bir düzeyin altında olması gerektiği belirtilmesine rağmen göl suları için böyle bir limit değer bulunmamaktadır. Dolayısıyla, çalışılan göl suyu içme suyu kriterlerine göre değerlendirilmiştir. Türkiye Cumhuriyeti Sağlık Bakanlığı tarafindan hazırlanarak 17/02/2005 tarih ve 25730 sayılı Resmi Gazete'de yayımlanarak yürürlüğe giren "İnsani Tüketim Amaçlı Sular Hakkındaki Yönetmelik”in içme sularına ilişkin radyolojik parametreler kısmında trityum düzeyi için sınır değer $100 \mathrm{~Bq} / \mathrm{L}$ olarak belirtilmiştir (TCSB, 2005).

Tablo 1. Göl suyu örneklerinin alındığı koordinatlar ve örneklerin trityum konsantrasyonları

Table 1. The coordinates which lake water samples were taken and tritium concentrations of samples

\begin{tabular}{lcccc}
\hline \multirow{2}{*}{ Örnek Kodu } & \multicolumn{2}{c}{ GPS Koordinatları } & \multicolumn{2}{c}{ Trityum Konsantrasyonu } \\
\cline { 2 - 5 } & Enlem $(\mathbf{N})$ & Boylam $(\mathbf{E})$ & $\mathbf{B q} / \mathbf{L}$ & TU \\
\hline S-1 & $40^{\circ} 37^{\prime} 5.63^{\prime \prime}$ & $40^{\circ} 46^{\prime} 43.84^{\prime \prime}$ & $3,20 \pm 0,40$ & $27,11 \pm 3,42$ \\
S-2 & $40^{\circ} 37^{\prime} 5.59^{\prime \prime}$ & $40^{\circ} 46^{\prime} 45.14^{\prime \prime}$ & $3,39 \pm 0,38$ & $28,73 \pm 3,21$ \\
S-3 & $40^{\circ} 37^{\prime} 5.60^{\prime \prime}$ & $40^{\circ} 46^{\prime} 46.53^{\prime \prime}$ & $2,51 \pm 0,35$ & $21,30 \pm 2,93$ \\
S-4 & $40^{\circ} 37^{\prime} 5.59^{\prime \prime}$ & $40^{\circ} 46^{\prime} 47.76^{\prime \prime}$ & $2,98 \pm 0,33$ & $25,23 \pm 2,82$ \\
S-5 & $40^{\circ} 37^{\prime} 6.96^{\prime \prime}$ & $40^{\circ} 46^{\prime} 48.07^{\prime \prime}$ & $2,76 \pm 0,31$ & $23,39 \pm 2,66$ \\
S-6 & $40^{\circ} 37^{\prime} 6.93^{\prime \prime}$ & $40^{\circ} 46^{\prime} 46.71^{\prime \prime}$ & $3,47 \pm 0,36$ & $29,40 \pm 3,04$ \\
S-7 & $40^{\circ} 37^{\prime} 6.89^{\prime \prime}$ & $40^{\circ} 46^{\prime} 45.15^{\prime \prime}$ & $2,60 \pm 0,59$ & $22,00 \pm 5,04$ \\
S-8 & $40^{\circ} 37^{\prime} 6.86^{\prime \prime}$ & $40^{\circ} 46^{\prime} 43.71^{\prime \prime}$ & $2,87 \pm 0,37$ & $24,33 \pm 3,14$ \\
S-9 & $40^{\circ} 37^{\prime} 8.37^{\prime \prime}$ & $40^{\circ} 46^{\prime} 45.18^{\prime \prime}$ & $2,75 \pm 0,63$ & $23,30 \pm 5,31$ \\
S-10 & $40^{\circ} 37^{\prime} 8.31^{\prime \prime}$ & $40^{\circ} 46^{\prime} 46.86^{\prime \prime}$ & $2,55 \pm 0,49$ & $21,63 \pm 4,13$ \\
S-11 & $40^{\circ} 37^{\prime} 8.27^{\prime \prime}$ & $40^{\circ} 46^{\prime} 48.34^{\prime \prime}$ & $2,51 \pm 0,63$ & $21,24 \pm 5,31$ \\
S-12 & $40^{\circ} 37^{\prime} 9.72^{\prime \prime}$ & $40^{\circ} 46^{\prime} 48.64^{\prime \prime}$ & $2,63 \pm 0,58$ & $22,32 \pm 4,91$ \\
S-13 & $40^{\circ} 37^{\prime} 9.79^{\prime \prime}$ & $40^{\circ} 46^{\prime} 47.07^{\prime \prime}$ & $2,82 \pm 0,50$ & $23,89 \pm 4,22$ \\
S-14 & $40^{\circ} 37^{\prime} 9.88^{\prime \prime}$ & $40^{\circ} 46^{\prime} 45.21^{\prime \prime}$ & $3,53 \pm 0,60$ & $29,87 \pm 5,12$ \\
S-15 & $40^{\circ} 37^{\prime} 9.99^{\prime \prime}$ & $40^{\circ} 46^{\prime} 43.37^{\prime \prime}$ & $2,58 \pm 0,49$ & $21,83 \pm 4,16$ \\
\hline
\end{tabular}


Yine, Avrupa Komisyonu tarafindan içme sularında trityum konsantrasyonu için önerilen sinır değer $100 \mathrm{~Bq} / \mathrm{L}$ olarak verilmektedir (EC, 1998). Uluslararası bir kuruluş olan Dünya Sağlık Örgütü ise içme sularında trityum konsantrasyonu için limit değeri $10000 \mathrm{~Bq} / \mathrm{L}$ olarak önermektedir (WHO, 2011). Bu araştırma sonucunda Ovit Dağbaşı Gölünün sularında belirlenen trityum konsantrasyon değerleri (Tablo 1), ulusal ve uluslararası kuruluşlar tarafindan önerilen bu değerlerden oldukça düşük bulunmuştur. Dolayısıyla, çalışılan Ovit Dağbaşı Gölünün suları için trityum radyoizotopu açısından herhangi bir radyolojik risk görülmemektedir.
Dünyada göl sularında trityum konsantrasyonlarının belirlenmesi üzerine yapılmış çalışmalar bulunmaktadır. Ovit Dağbaşı Gölü suyunda belirlenen ortalama trityum konsantrasyonu ABD'deki Huron Gölü suyunda belirlenen trityum konsantrasyonundan $(7,4 \mathrm{~Bq} / \mathrm{L})$ daha düşük (Lickly vd., 1983), Kanada'daki Ontario Gölü suyunda belirlenen trityum konsantrasyonundan $(<0,6 \mathrm{~Bq} / \mathrm{L})$ ise daha yüksek bulunmuştur (Kim vd., 2018). Bu konsantrasyon farklılıklarının trityumun çevresel olarak büyük ölçüde değişkenlik göstermesinden kaynaklanabileceği söylenebilir.

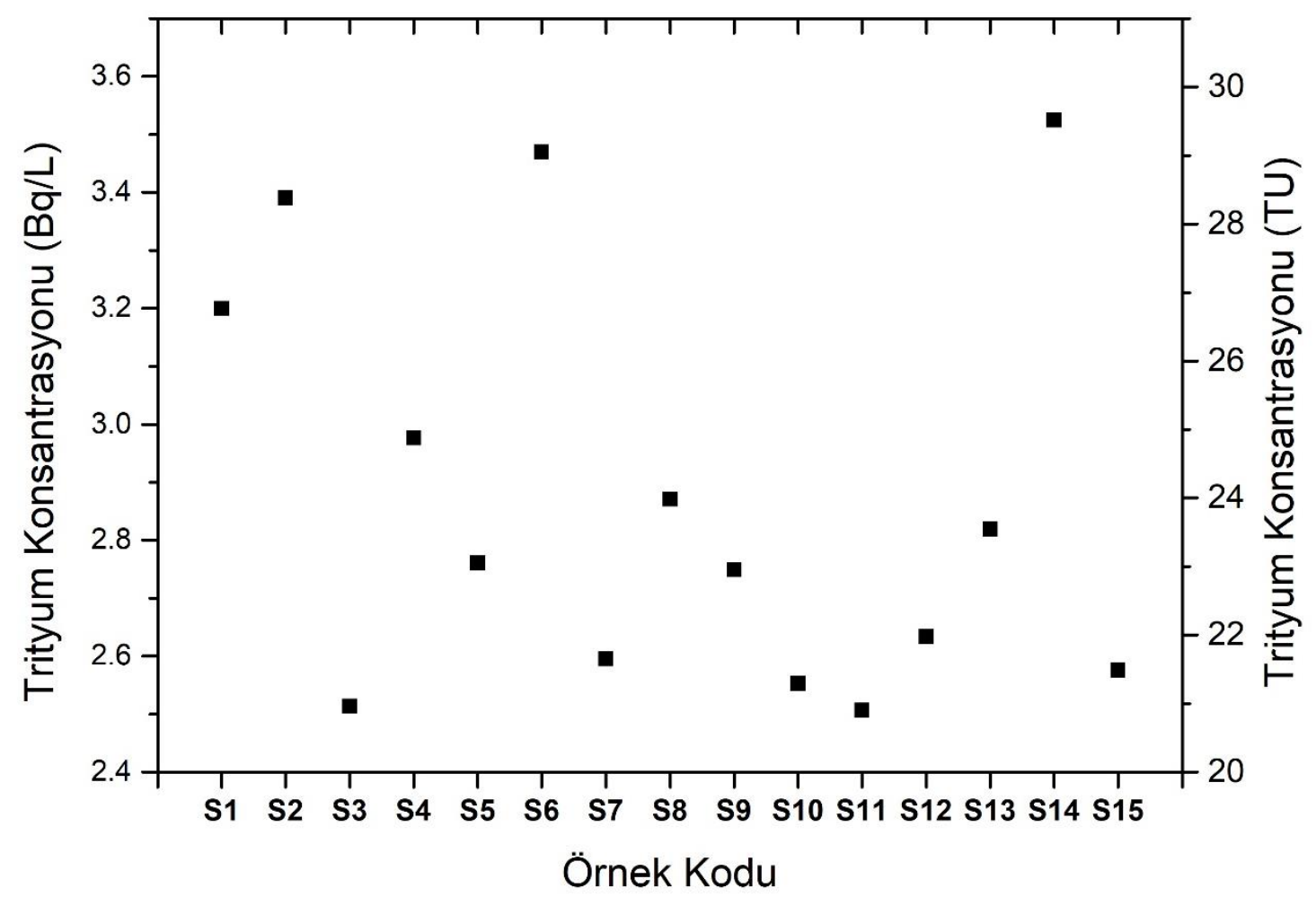

Şekil 2. Göl suyu örneklerinde belirlenen trityum konsantrasyonları

Figure 2. Tritium concentrations determined in the lake water samples

Çalışmada kullanılan germanyum dedektörü için minimum ölçülebilir aktivite (MDA) değerleri ${ }^{226} \mathrm{Ra},{ }^{232} \mathrm{Th}$ ve ${ }^{40} \mathrm{~K}$ radyoizotopları için sırasıyla $0,24 \mathrm{~Bq} / \mathrm{L}, 0,21 \mathrm{~Bq} / \mathrm{L}$ ve 2,49 $\mathrm{Bq} / \mathrm{L}$ olarak hesaplandı. Ovit Dağbaşı Gölünden alınan su örneklerinde belirlenen ${ }^{226} \mathrm{Ra}, \quad{ }^{232} \mathrm{Th}$ ve ${ }^{40} \mathrm{~K}$ 'n aktivite konsantrasyonları Tablo 2'de verilmektedir. ${ }^{226} \mathrm{Ra}, \quad{ }^{232} \mathrm{Th} \quad$ ve ${ }^{40} \mathrm{~K}$ ' $\mathrm{n} \quad$ aktivite konsantrasyonlar1 sirasiyla $0,36-2,82 \quad \mathrm{~Bq} / \mathrm{L}$, $0,37-1,92 \mathrm{~Bq} / \mathrm{L}$ ve $13,28-20,96 \mathrm{~Bq} / \mathrm{L}$ aralığında değişmekte olup, ortalama aktivite konsantrasyonları ${ }^{226} \mathrm{Ra}$ için $1,80 \pm 0,54 \mathrm{~Bq} / \mathrm{L}$, ${ }^{232} \mathrm{Th}$ için $1,13 \pm 0,51 \quad \mathrm{~Bq} / \mathrm{L}$ ve ${ }^{40} \mathrm{~K}$ için $17,22 \pm 2,61 \quad \mathrm{~Bq} / \mathrm{L}$ olarak bulunmuştur. İncelenen su örneklerinde belirlenen radyoaktivite konsantrasyonları grafiksel olarak Şekil 3’te ayrıca gösterilmektedir. Göl 
sularında doğal radyoaktivite düzeyleri ile ilgili önerilen bir değer bulunmamaktadır ancak Dünya Sağl1k Örgütü (WHO) tarafından içme sularında ${ }^{226} \mathrm{Ra}$ radyoizotopunun $\leq 10$ $\mathrm{Bq} / \mathrm{L}$ ve ${ }^{232} \mathrm{Th}$ radyoizotopunun ise $\leq 1 \mathrm{~Bq} / \mathrm{L}$ olması önerilmektedir (WHO, 2004). Göl suyu örneklerinde belirlenen ${ }^{226} \mathrm{Ra}$ ve ${ }^{232} \mathrm{Th}$ 'nin ortalama aktivite konsantrasyonlarına bakıldığında, incelenen göl sularının radyoaktivite yönünden WHO tarafindan önerilen kriterleri sağladığı söylenebilir. Dünyada göl sularında doğal radyoaktivite konsantrasyonlarının belirlenmesi üzerine yapılmış çalışmalar mevcuttur. Göl suyu örneklerinde doğal radyoaktivite konsantrasyonlarının belirlendiği bu çalışma ve farklı ülkelerde yapılmış olan çalışmalarda bulunan ortalama ${ }^{226} \mathrm{Ra},{ }^{232} \mathrm{Th}$ ve ${ }^{40} \mathrm{~K}$ konsantrasyonları Tablo 3'te verilmektedir.

Tablo 2. Ovit Dağbaşı Gölünden alınan su örneklerinde ${ }^{226} \mathrm{Ra},{ }^{232} \mathrm{Th}$ ve ${ }^{40} \mathrm{~K}$ konsantrasyonları Table 2. ${ }^{226} \mathrm{Ra},{ }^{232}$ Th ve ${ }^{40} \mathrm{~K}$ concentrations in water samples taken from Ovit Dağbaşı Lake

\begin{tabular}{lccc}
\hline \multirow{2}{*}{ Örnek Kodu } & \multicolumn{3}{c}{ Aktivite Konsantrasyonu $(\mathbf{B q} / \mathbf{L})$} \\
\cline { 2 - 4 } & ${ }^{226} \mathbf{R a}$ & ${ }^{232} \mathbf{T h}$ & ${ }^{40} \mathbf{K}$ \\
\hline S-1 & $0,36 \pm 0,15$ & $0,43 \pm 0,21$ & $13,28 \pm 1,53$ \\
S-2 & $2,28 \pm 0,62$ & $1,92 \pm 0,52$ & $13,85 \pm 3,55$ \\
S-3 & $1,65 \pm 0,48$ & $0,82 \pm 0,53$ & $19,11 \pm 2,10$ \\
S-4 & $1,52 \pm 0,66$ & $1,37 \pm 0,62$ & $17,86 \pm 2,53$ \\
S-5 & $1,54 \pm 0,48$ & $0,37 \pm 0,48$ & $14,07 \pm 2,79$ \\
S-6 & $2,20 \pm 0,59$ & $1,10 \pm 0,56$ & $18,56 \pm 3,26$ \\
S-7 & $1,78 \pm 0,52$ & $1,33 \pm 0,50$ & $15,68 \pm 2,63$ \\
S-8 & $2,35 \pm 0,65$ & $1,71 \pm 0,55$ & $18,80 \pm 3,02$ \\
S-9 & $1,67 \pm 0,52$ & $1,01 \pm 0,45$ & $16,54 \pm 1,99$ \\
S-10 & $2,82 \pm 0,67$ & $1,45 \pm 0,59$ & $17,81 \pm 3,02$ \\
S-11 & $2,09 \pm 0,49$ & $1,19 \pm 0,42$ & $16,19 \pm 2,31$ \\
S-12 & $1,79 \pm 0,60$ & $1,25 \pm 0,60$ & $18,16 \pm 2,92$ \\
S-13 & $1,46 \pm 0,52$ & $1,14 \pm 0,46$ & $19,71 \pm 2,17$ \\
S-14 & $1,56 \pm 0,65$ & $0,95 \pm 0,63$ & $17,79 \pm 3,16$ \\
S-15 & $1,90 \pm 0,51$ & $0,84 \pm 0,46$ & $20,96 \pm 2,18$ \\
\hline
\end{tabular}

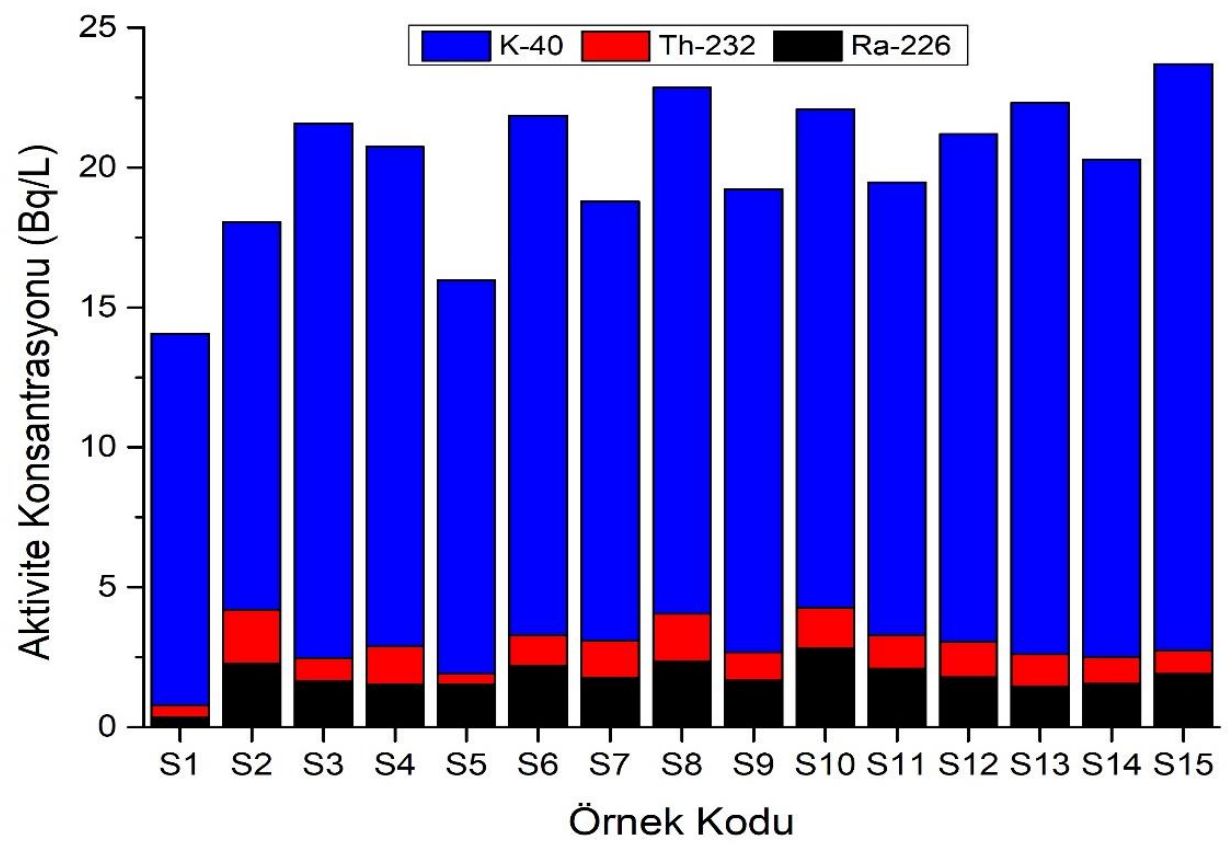

Şekil 3. Göl suyu örneklerinde belirlenen ${ }^{226} \mathrm{Ra},{ }^{232} \mathrm{Th}$ ve ${ }^{40} \mathrm{~K}$ konsantrasyonları

Figure 3. ${ }^{226} \mathrm{Ra},{ }^{232} \mathrm{Th} v e{ }^{40} \mathrm{~K}$ concentrations determined in the lake water samples 
Tablo 3. Göl suyu örneklerindeki aktivite konsantrasyonlarının literatürdeki bazı çalışmalarla karşılaştırılması

Table 3. Comparison of activity concentrations in lake water samples with some studies in the literature

\begin{tabular}{lcccl}
\hline \multirow{2}{*}{ Ülke, Göl } & \multicolumn{3}{c}{ Aktivite Konsantrasyonu $(\mathbf{B q} / \mathbf{L})$} & \multirow{2}{*}{ Referans } \\
\cline { 2 - 4 } & ${ }^{\mathbf{2 2 6}} \mathbf{R a}$ & ${ }^{\mathbf{2 3 2}} \mathbf{T h}$ & ${ }^{\mathbf{4 0}} \mathbf{K}$ & \\
\hline Nijerya, Uburu & 1,22 & 4,17 & 9,82 & Ononugbo ve Nwaka, 2017 \\
Misır, Nasser & 0,43 & 0,45 & 4,70 & İmam vd., 2020 \\
Misır, Qarun & 6,40 & 3,20 & 31,30 & Amin, 2013 \\
Türkiye, Ovit Dağbaş1 & 1,80 & 1,13 & 17,22 & Bu çalışma \\
\hline
\end{tabular}

Tablo 3'te görüldüğü üzere, bu çalışmada incelenen göl suyu örneklerinde belirlenen ortalama ${ }^{226} \mathrm{Ra}$ konsantrasyonu Qarun Göl sularının konsantrasyonlarından düşük, Uburu ve Nasser Göl sularındaki konsantrasyonlardan ise daha yüksek bulunmuştur. Yine, incelenen göl suyu örneklerinde belirlenen ortalama ${ }^{232} \mathrm{Th}$ konsantrasyonu Nasser Gölü hariç diğerlerinden düşük bulunmuştur. Bunların yanında, göl suyu örneklerinde belirlenen ortalama ${ }^{40} \mathrm{~K}$ konsantrasyonları ise Qarun Gölü hariç diğerlerinden daha yüksek bulunmuştur.

\section{Sonuç}

Ovit Dağbaşı Gölünden alınan 15 adet su numunesinde trityum $(3 \mathrm{H})$ konsantrasyonları Siv1 Sintilasyon Sayac1 (Perkin Elmer) ile ${ }^{226} \mathrm{Ra},{ }^{232} \mathrm{Th}$ ve ${ }^{40} \mathrm{~K}$ konsantrasyonları ise Yüksek Saflıkta Germanyum Dedektörü (ORTEC) kullanılarak belirlendi. Su örneklerinde belirlenen trityum konsantrasyonları T.C. Sağlık Bakanlığı tarafından önerilen limitlerden oldukça düşük bulunmuştur. ${ }^{226} \mathrm{Ra}$ ve ${ }^{232} \mathrm{Th}$ konsantrasyonları ise Dünya Sağlık Örgütü tarafindan önerilen limitler içerisinde bulunmuştur. Sonuç olarak, incelenen göl sularının insan sağlığı açısından herhangi bir risk oluşturmadığı söylenebilir. Bunun yanında, elde edilen sonuçların çevresel radyoaktivite veritabanına katkı sağlayacağ 1 muhtemeldir.

\section{Author's ORCID ID}

Selim Sar1, 0000-0003-4914-3339

\section{Referanslar}

Amin, R.M. (2013). Radioactivity levels in some sediments and water samples from Qarun Lake by low-level gamma spectrometry. International Journal of Science and Research, 2319-7064.

ASTM D4107-08 (2006). Standard Test Method for Tritium in Drinking Water. ASTM International, West Conshohocken, http://dx.doi.org/10.1520/D4107-08.

Currie, L.A. (1968). Limits for qualitative detection and quantitative determination. Analytical Chemistry, 40, 586-593.

Dizman, S., Kağanoğlu, Ç.F., İpek, N., Keser, R. (2018). Assessments of tritium concentration in the some water samples around Rize. Turkish Journal of Materials, 3(1), 53-57.

Dizman, S., Görür, F.K., Keser, R., Görür, O. (2019). The assessment of radioactivity and radiological hazards in soils of Bolu province, Turkey. Environmental Forensics, 20, 211-218.

Dizman, S., Mukhtarli, O. (2021). Tritium concentrations and consequent doses in bottled natural and mineral waters sold in Turkey and Azerbaijan. Chemosphere, 267, 128721.

EC, (1998). Council Directive 98/83/EC of November 3 on the quality of water intended for human consumption. Official Journal of the European Communities, L330/32-330/54.

Grigorescu, E.L., Cristina Razdolescu, A., Sahagia, M., Luca, A., Ivan, C., Tanase, G. (2002). Standardization of Eu-152. Applied Radiation and Isotopes, 56, 435-439.

Imam, N., El-Sayed, S.M., El-Sherif Goher, M. (2020). Risk assessments and spatial distributions of natural radioactivity and heavy metals in Nasser Lake, Egypt. Environmental Science and Pollution Research, 27, 2547525493.

Kavun, Y., Boztosun, İ., Dapo, H., Maraş, İ., Segebade, C. (2018). Determination of the 
$\mathrm{Sr} / \mathrm{Ca}$ ratio of tooth samples by photoactivation analysis in Southern Turkey. Radiochimica Acta, 106(9), 759-768.

Kim, S.B., Rowan, D., Chen, J., Rodgers, C.M.C., Rennie, M.D. (2018). Tritium in fish from remote lakes in northwestern Ontario, Canada. Journal of Environmental Radioactivity, 195, 104-108.

Lickly, T.D., Blanchard, F.A., Takahashi, I.T. (1983). Survey of tritium radioactivity in Lake Huron surface water. Environment International, 9, 221-224.

Ononugbo, C.P., Nwaka, B.U. (2017). Natural Radioactivity and Radiological Risk Estimation of Drinking Water from Okposi and Uburu Salt Lake Area, Ebonyi State, Nigeria. Physical Science International Journal, 15(3), 1-15.

Otansev, P., Taşkın, H., Başsarı, A., Varinlioğlu, A. (2016). Distribution and environmental impacts of heavy metals and radioactivity in sediment and seawater samples of the Marmara Sea.
Chemosphere, 154, 266-275.

Palomo, M., Penalver, A., Aguilar, C., Borrull, F. (2007). Tritium activity levels in environmental water samples from different origins. Applied Radiation and Isotopes, 65, 1048-1056.

TCSB, (2005). İnsani Tüketim Amaclı Sular Hakkında Yönetmelik. Official Journal 25730, Turkey.

UNSCEAR, (1993). Exposure from Natural Sources of Radiation of Radiation. Report to the General Assembly. United Nations, 1993.

URL-1, (2020). https://www.kulturportali.gov.tr/ turkiye/rize/gezilecekyer/ovit-dagbasi-golu, 02 Şubat 2021

WHO, (2004). Guidelines for drinking water quality. First Addendum to the 3rd edn., vol 1 recommendations, 491-493.

WHO, (2011). Library Cataloguing in Publication Data NLM classification: WA 675. 